\section{Engajamento cívico e internet. Notas de pesquisa, a partir de uma tipologia}

\author{
Davide Carbonai \\ \& Paulo Ricardo Zilio Abdala*
}

Resumo: O uso da internet como meio de participação política - também conhecido como participação política eletrônica - representa um tema de interesse sociológico crescente, ainda que a literatura destaque a escassez de pesquisas empíricas sobre o assunto. Este artigo apresenta uma pesquisa desenvolvida a partir de uma coleta de dados por questionário (uma amostragem de 389 entrevistados), tendo como principal objetivo obter um mapa da participação e da cultura política no Pampa (mais especificamente, o município de São Borja, na fronteira oeste do estado do Rio Grande do Sul). O artigo analisa a relação entre tipos de usuário da internet - uma tipologia de participação política eletrônica - e as formas mais tradicionais de civismo: um índice construído a partir de indicadores de participação e envolvimento em associações cívicas. A análise demonstra que não é por causa do ativismo político nas redes sociais e demais meios digitais que uma pessoa está disposta a se engajar efetivamente em organizações da sociedade civil.

Palavras-chave: cultura política; participação política eletrônica; internet, Pampa.

\section{Introdução}

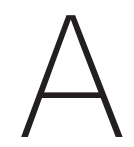
difusão da internet, no início da década de 1990, a multiplicação de sites e blogs com caráter político e social, bem como o ativismo digital em suas diferentes nuances e práticas trouxeram enormes expectativas sobre a renovação das possibilidades de participação política e social. Wilson Gomes (2005) sugere que boa parte da participação política tradicional, off-line, poderia então ser realizada mediante o uso da internet: o contato e a pressão sobre os representantes eleitos, a formação da opinião pública, o engajamento e a participação em discussões sobre os negócios públicos, e até a afiliação a partidos ou movimentos da sociedade civil. Esta participação se efetiva principalmente de três formas:

1. por vias institucionalizadas, como na chamada "cidadania digital", fenômeno estudado no âmbito do movimento de governo eletrônico, com debates que remetem ao aprimoramento da democracia representativa por meio da ampliação do controle social (Diniz et alii, 2009; Ferreira, 2010: 102);

2. como ativismo digital, por parte de movimentos sociais (Garrett, 2006); e/ou
Recebido: 22.10 .15

Aprovado: 06.06.16

\author{
* Davide Carbonai \\ é doutor em \\ sociologia econômica \\ (Universitá di \\ Teramo), professor \\ do Programa de \\ Pós-graduação em \\ Administração e \\ do Programa de \\ Pós-graduação em \\ Ciência Política da \\ Universidade Federal \\ do Rio Grande do \\ Sul, Departamento \\ de Ciências \\ Administrativas. \\ <davide.carbonai@ \\ ufrgs.br>. \\ Paulo Ricardo Zilio \\ Abdala é docente \\ e pesquisador da \\ Universidade Federal \\ do Rio Grande do \\ Sul, Departamento \\ de Ciências \\ Administrativas, \\ Programa de \\ Pós-Graduação \\ em Administração \\ (PPGA). Atual \\ presidente da \\ Sociedade Brasileira \\ de Estudos \\ Organizacionais, \\ é doutor, mestre \\ e bacharel em \\ administração pela \\ UFRGS e membro do \\ Grupo de Pesquisa \\ Organização e Práxis \\ Libertadora. <http:// \\ www.ufrgs.br/ \\ organizacaoepraxis \\ libertadora>. <paulo. \\ abdala@ufrgs.br>.
}


3. como forma espontânea e descentralizada de participação política eletrônica (Dahlgren, 2007; Winkler, 2010).

Outra literatura tende a marcar as possibilidades oferecidas pela internet e as transformações efetivadas nos últimos anos a partir de duas vertentes: uma otimista, como apresentada por Fábio Oliveira (2013), e outra crítica, como em Andréia Lima, Juliana Silva, Liziany Medeiros e Jerônimo Tybushi (2015).

Ainda que formas de participação política possam ser realizadas por meio da internet, isto não permite afirmar que estas se traduzam diretamente em formas de participação ou engajamento cívico mais tradicionais, como aquelas apresentadas nos estudos clássicos de sociologia política (Verba \& Nie, 1972; Barnes \& Kaase, 1979). O presente artigo pretende mesmo aprofundar o estudo do fenômeno da internet como meio de participação política e suas relações com formas mais tradicionais de engajamento cívico. Ao considerar ainda a lacuna de trabalhos empíricos sobre o tema, esta pesquisa analisa um banco de dados, propondo algumas hipóteses a serem testadas na sequência. Para cumprir com os objetivos do trabalho, é proposta a utilização de uma tipologia de cidadania eletrônica baseada no tipo de utilização da internet; a tipologia foi inspirada em um modelo já proposto em uma survey de 2010, por parte do instituto de pesquisa italiano Demos (Demos \& Pi, 2010). Além disso, para compreender melhor a relação entre o uso da internet e as práticas de civismo, é desenvolvido um modelo de regressão no qual o engajamento cívico - representado por um índice de civismo definido a partir da participação do entrevistado em um conjunto de atividades de organizações da sociedade civil - é explicado hipoteticamente pelos diferentes tipos de uso da internet.

O estudo foi desenvolvido a partir do projeto de pesquisa "Cultura política em São Borja", financiado pelo Programa de Bolsas de Desenvolvimento Acadêmico (PBDA) da Universidade Federal do Pampa, em 2013. O projeto apresenta como principal objetivo obter um mapa da participação e da cultura política em São Borja, município da fronteira oeste do Rio Grande do Sul. Considerada a já mencionada escassez de estudos empíricos sobre o tema da participação política eletrônica, o artigo se concentra, sobretudo, na análise de dados. Resumidamente, os resultados da pesquisa indicam que há uma baixa correspondência entre tipos de usuários da internet e práticas de engajamento cívico, demonstrando que um grau mais significativo de ativismo nas redes sociais - e demais meios digitais - nem sempre corresponde a um maior engajamento prático-presencial em organizações da sociedade civil. Essas evidências apontam para algumas limitações da participação política eletrônica como espaço de engajamento político, reforçando a noção de participação como espetáculo (Anjos \& Ezequiel, 2011). 


\section{Procedimentos metodológicos}

A amostra da pesquisa totalizou 389 entrevistados (50,4\% de homens e 49,6\% de mulheres), todos com 16 anos ou mais de idade (os menores de 16 anos foram excluídos por não serem aptos ao voto). Em concordância com os dados do Censo 2010 (IBGE, 2010), 13,36\% dos entrevistados residiam no bairro Centro do município de São Borja, o restante em outros bairros incluídos na área urbana da cidade. Em cada bairro foram sorteados os quarteirões para realização das entrevistas, caracterizando um processo de amostragem estratificada e probabilística.

O questionário foi organizado de maneira a fornecer um panorama das principais características da cultura e da participação política no município de São Borja, composto por 45 perguntas, divididas em quatro blocos: hábito de uso da internet e outras mídias, confiança institucional, comportamento eleitoral e participação política. Além disso, foram incluídas questões relativas ao perfil dos entrevistados, utilizadas na análise como variáveis independentes: gênero, idade, nível de instrução e cor de pele. É importante destacar que o caso de São Borja é aqui utilizado de forma experimental, para testar uma hipótese sobre a relação entre participação política eletrônica e engajamento cívico (em suas formas mais tradicionais), remetendo a outros textos uma análise mais exaustiva sobre o específico contexto político e social da região (Carbonai \& Valença, 2015).

A análise de dados foi dividida em dois blocos. No primeiro, discutiu-se a tipologia de participação política eletrônica e sua associação bivariada com outros indicadores da cultura política e outras características da população; no segundo, desenvolveu-se um índice geral de civismo e sua relação com a participação política eletrônica, por meio de um modelo de análise de regressão. Como observado, a análise é baseada em uma tipologia do uso da internet. A tipologia de participação política eletrônica é construída a partir de três variáveis nominais dicotômicas, presentes no questionário, com opções de respostas "sim" ou "não",

QUADRO 1

conforme apresentado no Quadro 1.

VARIÁVEIS PARA A CONSTRUÇÃO DA TIPOLOGIA DE PARTICIPAÇÃO POLÍTICA ELETRÔNICA

A partir das variáveis presentes no Quadro 1, é possível recombinar as opções de resposta, até reconduzi-las nos quatro tipos que caracterizam a tipologia de participação política ele-

\section{No seu cotidiano, você:}

1. [...] utiliza a internet?

2. [...] lê jornais de política on-line?

3. [...] debate política on-line (na internet)?

Fonte: adaptado de Demos \& Pi (2010). trônica (ver Quadro 2). Enquanto os off-line não utilizam a internet, os internautas costumam utilizá-la, mas não leem jornais, nem debatem política on-line; os infonautas se informam sobre política on-line, mas não debatem; os civis.net represen- 
QUADRO 2

TIPOLOGIA DE PARTICIPAÇÃO POLÍTICA ELETRÔNICA

\begin{tabular}{|l|c|c|c|}
\multirow{2}{*}{ Tipo } & \multicolumn{3}{|c|}{ Variáveis } \\
\cline { 2 - 4 } & $\begin{array}{c}\text { P. 1 } \\
\text { Utiliza internet }\end{array}$ & $\begin{array}{c}\text { P. 2 } \\
\text { Lê jornais de política on-line }\end{array}$ & $\begin{array}{c}\text { P. 3 } \\
\text { Debate política on-line }\end{array}$ \\
\hline Off-lines & Não & - & - \\
\hline Internautas & $\operatorname{Sim}$ & Não & Não \\
\hline Infonautas & $\operatorname{Sim}$ & $\operatorname{Sim}$ & Não \\
\hline Civis.net & $\operatorname{Sim}$ & $\operatorname{Sim}$ & Sim \\
\hline
\end{tabular}

tam o caso da participação política eletrônica plena: são conectados à internet, são informados e debatem política on-line.

Na pesquisa social existem diferentes metodologias e técnicas para a definição de grupos; enquanto as técnicas de uma análise multivariada, devido a fatores extraídos (geralmente dois) explicam só uma parte da variância total, uma tipologia construída a partir de algumas variáveis categóricas permite anular a perda de informação típicas das análises multivariadas; infelizmente, do outro lado, o uso de variáveis categóricas é menos sensível à realidade do que as escalas Likert ou outras variáveis cardinais, utilizadas na análise fatorial.

1. As associações utilizadas na construção do índice de civismo são aquelas que apresentam maior relevância na região na qual foi conduzida a pesquisa. Além disso, o item "Outras associações" pretende, de qualquer forma, incluir no índice todas as demais associações e organizações de menor porte ou penetração social (Tabela 4).

Para comparar entre si os grupos, foi criado um índice de participação política - chamado de "índice de civismo" - a partir de algumas práticas cívicas: ativismo político, ativismo comunitário em uma associação de bairro, centros de tradições regionais, associação animalista, sindicato, participação nas reuniões do orçamento participativo, ativismo de vários tipos em outras associações ${ }^{1}$. Quanto mais "ativismos" atendidos, maior o índice, conforme a metodologia utilizada também por José Paulo Martins Junior e Humberto Dantas (2004). Afinal, com o conceito de "engajamento cívico" entendemos representar uma das muitas dimensões do conceito de "capital social": conforme Robert Putnam (1993) as redes de associativismo cívico favorecem a consolidação de comunidades mais eficientes e justas. Além disso, as associações cívicas cumprem duas principais funções: uma função interna, pelo fato de as associações produzirem hábitos de cooperação, solidariedade e espírito público; outra externa, favorecendo as agregações de interesses e o controle institucional. A partir dessas considerações, a pesquisa pretende responder a uma pergunta simples: os mais "ativos" nas redes sociais e na internet são também mais engajados em práticas cívicas associativas? 


\section{A participação política eletrônica}

Ao analisar a amostra em estudo, somente $8,1 \%$ dos entrevistados se enquadram na categoria de civis.net; já o número de infonautas é um pouco maior (16,6\%), mas ainda inferior aos que apenas navegam na internet sem interesse político declarado - os internautas (34,2\%). Por sua vez, os off-lines representam $41 \%$ da amostra.

A tipologia de participação política eletrônica foi associada às principais ca-

TABELA 1

TIPOLOGIA DA PARTICIPAÇÃO POLÍTICA ELETRÔNICA EM SÃO BORJA

\begin{tabular}{|l|c|c|}
\cline { 2 - 3 } \multicolumn{1}{c|}{} & Frequências & $\%$ \\
\hline Civis.net & 30 & $8,1 \%$ \\
\hline Infonautas & 61 & $16,6 \%$ \\
\hline Internautas & 126 & $34,2 \%$ \\
\hline Off-lines & 151 & $41 \%$ \\
\hline Total (N) & 368 & $100 \%$ \\
\hline Não responderam & 21 & \multirow{2}{*}{} \\
\cline { 1 - 2 } Total & 389 \\
\hline \multicolumn{2}{|l|}{ Fonte: coleta de dados (2013). }
\end{tabular}
racterísticas dos entrevistados, conforme apresentado na Tabela 2: gênero, idade, escolaridade, profissão e cor de pele. Em linhas gerais, o teste do qui-quadrado demonstra uma associação significativa entre as variáveis, com exclusão do item "cor de pele". Considerados os valores do

TABELA 2

TIPOLOGIA DA UTILIZAÇÃO POLÍTICA DA INTERNET E VARIÁVEIS DEMOGRÁFICAS

\begin{tabular}{|c|c|c|c|c|c|c|c|c|c|c|c|c|}
\hline \multirow{3}{*}{\multicolumn{2}{|c|}{ Tipos }} & \multirow{2}{*}{\multicolumn{2}{|c|}{$\frac{\text { Gênero }}{\text { (a) }}$}} & \multirow{2}{*}{\multicolumn{2}{|c|}{$\begin{array}{l}\text { Idade } \\
\text { (b) }\end{array}$}} & \multirow{2}{*}{\multicolumn{3}{|c|}{ Escolaridade }} & \multirow{2}{*}{\multicolumn{2}{|c|}{$\begin{array}{c}\text { Profissão } \\
\text { (d) }\end{array}$}} & \multirow{2}{*}{\multicolumn{2}{|c|}{$\begin{array}{c}\text { "Você se considera } \\
\text { (e) }\end{array}$}} \\
\hline & & & & & & & & & & & & \\
\hline & & $\mathrm{H}$ & M & $\begin{array}{l}\text { Até } 64 \\
\text { anos }\end{array}$ & $\begin{array}{l}\text { Acima } \\
\text { de } 64 \\
\text { anos }\end{array}$ & $\begin{array}{l}\text { Funda- } \\
\text { mental }\end{array}$ & Médio & $\begin{array}{l}\text { Supe- } \\
\text { rior (e } \\
\text { outros) }\end{array}$ & $\begin{array}{l}\text { Profis- } \\
\text { sões não } \\
\text { manuais }\end{array}$ & $\begin{array}{l}\text { Profis- } \\
\text { sões } \\
\text { manuais }\end{array}$ & Branco & $\begin{array}{l}\text { Negro } \\
\text { (outros } \\
\text { grupos) }\end{array}$ \\
\hline \multirow{3}{*}{ Civis.net } & $\mathrm{N}$ & 17 & 13 & 26 & 1 & 1 & 8 & 11 & 12 & 7 & 10 & 17 \\
\hline & $\%$ & $9,8 \%$ & $6,7 \%$ & $8,8 \%$ & $1,4 \%$ & ,9\% & $6,7 \%$ & $15,1 \%$ & $10,0 \%$ & $5,0 \%$ & $9,3 \%$ & $7,1 \%$ \\
\hline & Stand. Res. & 0,7 & $-0,7$ & 0,9 & $-1,8$ & $-2,4 * *$ & 0,1 & $2,9^{*}$ & 1,1 & $-1,0$ & ,6 &,- 4 \\
\hline \multirow{3}{*}{ Infonautas } & $\mathrm{N}$ & 41 & 20 & 59 & 2 & 7 & 21 & 20 & 25 & 20 & 18 & 42 \\
\hline & $\%$ & $23,6 \%$ & $10,3 \%$ & $20,0 \%$ & $2,9 \%$ & $6,0 \%$ & $17,6 \%$ & $27,4 \%$ & $20,8 \%$ & $14,3 \%$ & $16,7 \%$ & $17,4 \%$ \\
\hline & Stand. Res. & $2,3^{*}$ & $-2,1^{* *}$ & 1,4 & $-2,8^{* *}$ & $-2,6 * *$ & 0,6 & $2,6^{*}$ & 9 &,- 9 &,- 1 & 1 \\
\hline \multirow{3}{*}{ Internautas } & $\mathrm{N}$ & 55 & 71 & 125 & 0 & 7 & 52 & 35 & 55 & 35 & 35 & 90 \\
\hline & $\%$ & $31,6 \%$ & $36,6 \%$ & $42,4 \%$ &, $0 \%$ & $6,0 \%$ & $43,7 \%$ & $47,9 \%$ & $45,8 \%$ & $25,0 \%$ & $32,4 \%$ & $37,3 \%$ \\
\hline & Stand. Res. & $-0,6$ & 0,6 & $2,4^{*}$ & $-4,9 * *$ & $-4,8 * *$ & $2,6^{*}$ & $2,7^{*}$ & $2,1^{*}$ & $-1,9$ &,- 6 & , 4 \\
\hline \multirow{3}{*}{ Off-lines } & $\mathrm{N}$ & 61 & 90 & 85 & 66 & 102 & 38 & 7 & 28 & 78 & 45 & 92 \\
\hline & $\%$ & $35,1 \%$ & $46,4 \%$ & $28,8 \%$ & $95,7 \%$ & $87,2 \%$ & $31,9 \%$ & $9,6 \%$ & $23,3 \%$ & $55,7 \%$ & $41,7 \%$ & $38,2 \%$ \\
\hline & Stand. Res. & $-1,2$ & 1,2 & $-3,4 * *$ & $7,0^{*}$ & $6,2^{*}$ & $-2,5 * *$ & $-4,7 * *$ & $-3,0 * *$ & $2,8^{*}$ & ,4 &,- 3 \\
\hline \multirow{2}{*}{ Total } & $\mathrm{N}$ & 174 & 194 & 295 & 69 & 117 & 119 & 73 & 120 & 140 & 108 & 241 \\
\hline & $\%$ & $100 \%$ & $100 \%$ & $100 \%$ & $100 \%$ & $100 \%$ & $100 \%$ & $100 \%$ & $100 \%$ & $100 \%$ & $100 \%$ & $100 \%$ \\
\hline
\end{tabular}

*Standard Residual>2 (associação positíva entre as categorias); **Standard Residual<-2 (associação negativa entre as categorias); (a) Pearson Chi-Square = 4,39 ( $\mathrm{p}<0,01$ ); (b) Pearson Chi-Square $=103,30(p<0,01)$; (c) Pearson Chi-Square $=131,94(p<0,01)$; (d) Pearson Chi-Square $=28,52(p<0,01)$; (e) Pearson Chi-Square $=1,23$ (não significativo). Fonte: Coleta de Dados (2013). 
teste do qui-quadrado e a distribuição de frequência por categorias, em linha geral, é sobretudo entre os diferentes níveis de escolaridade, idade e estratificação social que se encontram elementos típicos da exclusão digital.

No que se refere ao gênero, existe uma participação maior de homens no tipo infonautas, enquanto as mulheres são mais frequentes nos tipos off-lines e internautas (ver a distribuição dos resíduos padronizados). Além disso, há uma diferença mais evidente no que refere aos grupos etários; enquanto a idade média dos off-lines é igual a 58 anos, a dos Infonautas é 39, a dos civis.net é 37, e a dos internautas 32. Outra característica que chama a atenção na amostra é a relação entre o tipo de ocupação e a utilização da internet: entre os off-lines, por exemplo, os trabalhadores manuais atingem o percentual de até $55,7 \%$. Por sua vez, $87,2 \%$ dos não alfabetizados, ou com ensino fundamental completo, encontram-se entre os off-lines, enquanto a este tipo corresponde apenas 9,6\% dos entrevistados com nível de ensino superior. Ou seja, quanto maior o grau de escolaridade, maior a propensão a ser incluído entre os civis.net ou os infonautas, demonstrando uma associação positiva entre nível escolar e participação política eletrônica.

Na Tabela 3 é apresentado o cruzamento bivariado entre os tipos da participação política eletrônica e alguns traços da cultura política local: (a) o capital social (mais especificamente, a dimensão da confiança interpessoal); (b) a renúncia ao voto em caso de não obrigatoriedade; (c) a filiação partidária; e $(d)$ os conhecimentos básicos sobre o orçamento participativo na região. Na Tabela 3 é possível observar que o cruzamento entre as variáveis de cultura política com a tipologia da internet apresenta uma associação estatística significativa, senão em relação ao item "confiança interpessoal". Em outros termos, a confiança interpessoal não se modifica significativamente entre os diferentes tipos de participação política eletrônica. Por sua vez, o cruzamento das demais variáveis apresenta uma associação significativa: o percentual de indivíduos que não abriria mão do voto mesmo que ele não fosse obrigatório é de quase $90 \%$ entre os civis.net e de $48,7 \%$ entre os off-lines; o percentual de afiliados em um partido é de $37,9 \%$ entre os civis.net, mas desce até $8,0 \%$ entre os off-lines. Já no que se refere ao conhecimento sobre o orçamento participativo regional, o percentual de "sim" entre os civis.net chega a 93,3\%, caindo até $33,3 \%$ entre os off-lines.

Estes dados conferem validade nomológica para a tipologia, demonstrando que a participação política eletrônica se relaciona positivamente com algumas atitudes políticas, especialmente no que se refere ao posicionamento com relação à democracia representativa. Entretanto, tais atitudes não se traduzem em práticas de engajamento em organizações da sociedade civil. 
TABELA 3

TIPOLOGIA DE CIDADANIA ELETRÔNICA E TRAÇOS DA CULTURA POLÍTICA

\begin{tabular}{|c|c|c|c|c|c|c|}
\hline Variáveis & Alternativas & Estatísticas & Civis.net & Infonautas & Internautas & Off-lines \\
\hline \multirow{10}{*}{$\begin{array}{l}\text { (a) Confiança inter- } \\
\text { pessoal }\end{array}$} & \multirow{3}{*}{ É bom confiar nos outros } & $\mathrm{N}$ & 4 & 4 & 5 & 9 \\
\hline & & $\%$ & $13,3 \%$ & $6,6 \%$ & $4,0 \%$ & $6,0 \%$ \\
\hline & & Standard Residual & 1,6 & ,2 &,- 9 & 0 \\
\hline & \multirow{3}{*}{$\begin{array}{l}\text { É bom prestar muita aten- } \\
\text { ção }[\ldots]\end{array}$} & $\mathrm{N}$ & 21 & 51 & 96 & 121 \\
\hline & & $\%$ & $70,0 \%$ & $83,6 \%$ & $76,8 \%$ & $80,7 \%$ \\
\hline & & Standard Residual &,- 6 & ,4 &,- 3 & ,2 \\
\hline & \multirow{4}{*}{ É bom nunca confiar [...] } & $\mathrm{N}$ & 5 & 6 & 24 & 20 \\
\hline & & $\%$ & $16,7 \%$ & $9,8 \%$ & $19,2 \%$ & $13,3 \%$ \\
\hline & & Standard Residual & ,2 & $-1,0$ & 1,2 &,- 5 \\
\hline & & & $100 \%$ & $100 \%$ & $100 \%$ & $100 \%$ \\
\hline \multirow{7}{*}{$\begin{array}{l}\text { (b) Abriria mão do } \\
\text { voto se o voto não } \\
\text { fosse obrigatório }\end{array}$} & \multirow{3}{*}{ Não } & $\mathrm{N}$ & 24 & 40 & 72 & 73 \\
\hline & & $\%$ & $88,9 \%$ & $65,6 \%$ & $57,6 \%$ & $48,7 \%$ \\
\hline & & Standard Residual & $2,1^{*}$ & 8 & , 0 & $-1,4$ \\
\hline & \multirow{4}{*}{ Sim } & $\mathrm{N}$ & 3 & 21 & 53 & 77 \\
\hline & & $\%$ & $11,1 \%$ & $34,4 \%$ & $42,4 \%$ & $51,3 \%$ \\
\hline & & Standard Residual & $-2,5 * *$ & $-1,0$ & 0 & 1,7 \\
\hline & & Total & $100 \%$ & $100 \%$ & $100 \%$ & $100 \%$ \\
\hline \multirow{7}{*}{$\begin{array}{l}\text { (c) Afiliação parti- } \\
\text { dária }\end{array}$} & \multirow{3}{*}{ Não } & $\mathrm{N}$ & 18 & 46 & 115 & 138 \\
\hline & & $\%$ & $62,1 \%$ & $75,4 \%$ & $92,7 \%$ & $92,0 \%$ \\
\hline & & Standard Residual & $-1,4$ & $-1,0$ & ,7 & 6 \\
\hline & \multirow{4}{*}{ Sim } & $\mathrm{N}$ & 11 & 15 & 9 & 12 \\
\hline & & $\%$ & $37,9 \%$ & $24,6 \%$ & $7,3 \%$ & $8,0 \%$ \\
\hline & & Standard Residual & $3,7^{*}$ & $2,5^{*}$ & $-1,8$ & $-1,7$ \\
\hline & & & $100 \%$ & $100 \%$ & $100 \%$ & $100 \%$ \\
\hline \multirow{7}{*}{$\begin{array}{l}\text { (d) Orçamento Par- } \\
\text { ticipativo }\end{array}$} & \multirow{3}{*}{ Não } & $\mathrm{N}$ & 1 & 8 & 29 & 58 \\
\hline & & $\%$ & $3,3 \%$ & $13,3 \%$ & $23,2 \%$ & $38,7 \%$ \\
\hline & & Standard Residual & $-2,5^{* *}$ & $-2,0$ &,- 7 & $3,0^{*}$ \\
\hline & \multirow{4}{*}{ Sim } & $\mathrm{N}$ & 28 & 47 & 63 & 50 \\
\hline & & $\%$ & $93,3 \%$ & $78,3 \%$ & $50,4 \%$ & $33,3 \%$ \\
\hline & & Standard Residual & $3,2^{*}$ & 2,9 &,- 2 & $-3,1$ \\
\hline & & & $100 \%$ & $100 \%$ & $100 \%$ & $100 \%$ \\
\hline
\end{tabular}

*Standard Residual > 2 (associação positiva entre as categorias) * * Standard Residual <-2 (associação negativa entre as categorias); (a) Pearson Chi-Square = 7,03 (não significativo); (b) Pearson Chi-Square = 17,31 ( $p<0,01)$; (c) Pearson Chi-Square $=30,28(p<0,01)$; (d) Pearson Chi-Square $=60,53(p<0,01)$.

Fonte: Coleta de Dados (2013).

\section{Participação política eletrônica e engajamento cívico}

O índice de engajamento cívico - também chamando de índice de civismo - foi constituído a partir de uma série de variáveis dicotômicas. A dimensão representada por cada variável corresponde a um critério geral de participação efetiva em uma 
atividade cívica, representada pela opção de resposta: "sim, geralmente participo da atividade desta entidade [...]".

A escolha das variáveis pretendeu contemplar o amplo campo do engajamento cívico: a dimensão política (partido político e orçamento participativo, pela sua ênfase na dimensão da inclusão política), a dimensão ocupacional (sindicato), a dimensão

TABELA 4

PARTICIPAÇÃO SOCIAL E ENGAJAMENTO CÍVICO (PERCENTUAL DE "SIM, GERALMENTE PARTICIPO DA ATIVIDADE DESTAS ENTIDADES [...]")

\begin{tabular}{|l|c|}
\hline Organizações da sociedade civil & Participantes na amostra (\%) \\
\hline Partido político & $12,8 \%$ \\
\hline Associação de bairro & $12,7 \%$ \\
\hline Centro trad.(CTG, PTG, etc.) & $14,3 \%$ \\
\hline Associação animalista & $2,1 \%$ \\
\hline Sindicato & $11,4 \%$ \\
\hline Orçamento participativo & $19,7 \%$ \\
\hline Outras associações & $14,0 \%$ \\
\hline Fonte: coleta de dados (2013). &
\end{tabular}

comunitária (associação de bairro e os centro tradicionalistas, também devido à atividade associativa, cultural, recreativa que desenvolvem em São Borja), a dimensão ambiental (associações animalistas), e o amplo espectro de associações minoritárias, mas não menos importantes (outras associações). Para a construção do índice de civismo foi considerada a prática associativa real e não só uma atitude política ou uma afiliação formal a um partido, como no caso das

variáveis constantes da Tabela 3. Além disso, não foi dada maior ou menor importância para os tipos de associação, com todas as variáveis apresentando o mesmo peso no índice (Tabela 4). O cidadão que participa plenamente seria aquele que soma sete pontos no índice de civismo; os mais próximos de zero seriam aqueles que não demonstram o menor interesse na participação cidadã.

TABELA 5

DISTRIBUIÇÃO DE FREQUÊNCIA DO ÍNDICE DE CIVISMO

A pontuação média do índice é cerca de 0,8 , ou seja, em média um entrevistado atende menos que uma atividade cívica. Entre os entrevistados, 53,1\% não atendem a nenhum dos itens incluídos no índice (pontuação zero no índice) e somente 4,4\% da população atende a quatro ou mais atividades cívicas.

As Tabelas 6 e 7 mostram as principais estatísticas do modelo de regressão da participação política

\begin{tabular}{|c|c|c|c|}
\hline $\begin{array}{c}\text { Índice de } \\
\text { civismo (0-7) }\end{array}$ & Frequências & Porcentagem & $\begin{array}{c}\text { Porcentagem } \\
\text { cumulada }\end{array}$ \\
\hline 0 & 204 & $53,1 \%$ & $53,1 \%$ \\
\hline 1 & 89 & $23,2 \%$ & $76,3 \%$ \\
\hline 2 & 52 & $13,5 \%$ & $89,8 \%$ \\
\hline 3 & 22 & $5,7 \%$ & $95,6 \%$ \\
\hline 4 & 12 & $3,1 \%$ & $98,7 \%$ \\
\hline 5 & 3 & $0,8 \%$ & $99,5 \%$ \\
\hline 6 & 1 & $0,3 \%$ & $99,7 \%$ \\
\hline 7 & 1 & $0,3 \%$ & $100 \%$ \\
\hline $\mathrm{N}$ & 384 & $100 \%$ & \\
\hline $\begin{array}{l}\text { Não } \\
\text { responderam }\end{array}$ & 5 & & \\
\hline Total & 389 & & \\
\hline
\end{tabular}


TABELA 6

RESUMO DO MODELO

\begin{tabular}{|c|c|c|c|c|}
\hline Modelo & $R$ & $R^{2}$ & $\begin{array}{l}R \text { quadrado } \\
\text { ajustado }\end{array}$ & $\begin{array}{l}\text { Erro padrão } \\
\text { da estimativa }\end{array}$ \\
\hline 1 & 0,20 & 0,040 & 0,03 & 1,17 \\
\hline
\end{tabular}

eletrônica no engajamento cívico. Três variáveis dummy (civis.net, infonautas e internautas) entram no modelo (enquanto os off-lines são considerados como va-

riável de controle); o modelo explica $4 \%$ da variância dos escores do engajamento (o valor $R^{2}$ ). Em outras palavras, $4 \%$ da variância nos escores do índice de engajamento é explicado pelo tipo de usuário da internet, conforme a nossa tipologia.

A ANOVA nos informa que o modelo é significantemente melhor em prever a mudança nos escores do engajamento cívico do que não ter um modelo (ou seja, $4 \%$ da variância explicada é uma quantia significativa) como também que as diferenças entre os valores médios dos grupos - ainda que significativas - são pouco relevantes.

\begin{tabular}{|c|c|c|c|c|c|}
\hline \multicolumn{6}{|c|}{$\begin{array}{c}\text { TABELA } 7 \\
\text { ANOVA }\end{array}$} \\
\hline Tipos & $\mathrm{N}$ & & $\begin{array}{l}\text { Desvio } \\
\text { padrão }\end{array}$ & $\mathrm{F}$ & Sig. \\
\hline Civis.net & 29 & 1,38 & 1,17 & \multirow{4}{*}{4,95} & \multirow{4}{*}{0,002} \\
\hline Infonautas & 61 & 1,25 & 1,19 & & \\
\hline Internautas & 124 & 0,74 & 1,04 & & \\
\hline Off-lines & 150 & 0,75 & 1,26 & & \\
\hline Total & 364 & 0,88 & 1,19 & & \\
\hline
\end{tabular}
Afinal, entre os civis.net o valor do índice é igual a 1,38 enquanto entre os off-lines é de 0,75 .

\section{Considerações finais}

Em primeiro lugar, o que a análise das tabelas de contingências demonstra é que as principais diferenças entre os quatro tipos de usuários da internet encontram-se na dimensão mais "formal" da cultura política ("afiliação" a um partido), ou em outras atitudes perante temas gerais da democracia ("não abriria mão do voto se não fosse obrigatório", "conhecer como funciona o orçamento participativo"); outras diferenças entre os tipos aparecem na associação com as "faixas etárias" e os "grupos profissionais", elementos que sinalizam a existência de diferenças relevantes no acesso ao meio digital. Marco Aurélio Ruediger (2002) já indicava que a relação com o mundo digital representa um fator crescente de assimetria social, aprofundando as disparidades socioeconômicas e espaciais entre aqueles que têm acesso aos sistemas digitais e os que não têm.

É importante sinalizar também outro aspecto: quando associadas com as práticas de participação em associações, as diferenças entre os tipos de usuários da internet se reduzem. Sobre a relação entre tipos e índice de civismo, os resultados vão ao 
encontro da hipótese de Gilda Anjos e Vanderlei Ezequiel (2011) sobre o crescimento do fenômeno político on-line apresentar efeito até contrário ao que promete: afinal, conforme os resultados da análise, os off-lines são mais engajados do que os internautas. Também reforça o alerta de Manuel Castells (1999) para quem a sociabilidade virtual funciona em outro plano, distinto dos elementos do real, apesar de não ser irreal, formando redes baseadas em laços fracos. Mas o que o artigo destaca é que, afinal, só uma parte residual dos entrevistados está ativamente envolvida em atividades cívicas, independentemente do tipo de uso da internet.

É importante também considerar o contexto regional fronteiriço do Rio Grande do Sul e suas especificidades, que podem esclarecer o valor médio do índice de engajamento (i.e., a sua baixa pontuação média). Alguns estudos apontam que as diferenças regionais no Rio Grande do Sul podem ser explicadas pelo diferente tipo de formação histórica regional, o que se reflete em uma diferente distribuição de capital social entre o "Norte colonial", com matriz de imigrantes europeus, e a matriz ibera, própria do "Sul", com o predomínio do latifúndio e do uso extensivo da mão de obra escrava (Bandeira, 2003; Monasterio, 2003; Santos et alii, 2010). Aliás, no que se refere ao caso do Pampa, a estrutura de poder montada em função da militarização da sociedade rio-grandense e a identificação do estancieiro como representante típico do "gaúcho do Pampa", ambos contribuíram para o surgimento de uma sociedade excludente (Baquero \& Reis, 2007: 38).

A pesquisa oferece enfim uma contribuição também em relação ao debate público mais atual: o fato de a internet poder levar muitas pessoas para as ruas não quer dizer que o uso do meio eletrônico possua relação direta com o engajamento cotidiano na vida política. De fato, a tipologia de utilização da internet explicou só uma pequena parte do engajamento cívico, ainda que significativa. Portanto, não há como predizer ou esperar que os indivíduos mais ativos nas discussões e na busca de informações sobre política na internet, tenham uma diferente inclinação a práticas cívicas mais engajadas e efetivas.

Abstract: The use of internet as a medium for political participation, also known as electronic political participation, represents a sociological issue of growing interest, though a review of literature shows scarce empirical researches about this subject. This paper presents a research developed from a survey data collection (sample of 389 individuals) having as a main goal to map the political culture and participation in the Pampa (more specifically, the city of São Borja, west frontier of Rio Grande do Sul). The paper analyzes the relation between a typology of internet users (an electronic political participation typology) and civic practices: a civicness index derived from indicators of participation and involvement in civic associations. The analysis demonstrates that political engagement in social networks or other digital media is not the reason why people engage effectively in civil society organizations.

Keywords: political culture; electronic political participation; internet; Pampa. 


\section{Referências}

ANJOS, Gilda; EZEQUIEL, Vanderlei. Cidadania virtual: o espetáculo do governo eletrônico. Estudos de Sociologia, v. 16, n. 30, p. 59-76, 2011.

BANDEIRA, Pedro. Algumas hipóteses sobre as causas das diferenças regionais quanto ao capital social no Rio Grande do Sul. In: CORREA, Silvio Marcus de Souza (Org.). Capital social e desenvolvimento regional, p.15-59. Santa Cruz do Sul: Edunisc, 2013.

BAQUERO, Marcello; REIS, Jussara P. A democracia brasileira e a cultura política no Rio Grande do Sul. Porto Alegre: UFRGS Editora, 2007.

BARNES, Samuel; KAASE, Max. Political action. Mass participation in five western democracies. Beverly Hills: Sage Publications, 1979.

CARBONAI, Davide; VALENÇA, Fernanda de Lima Mattos. Cultura política no Pampa. Revista Perspectivas em Políticas Públicas, v. 8, n. 15, p. 25-40, 2015.

CASTELLS, Manuel. A sociedade em rede. São Paulo: Paz e Terra,1999.

DAHLGREN, Peter. Young citizens and new media: learning for democratic participation. New York: Routledge, 2007.

DEMOS \& PI. Osservatorio sul capitale sociale degli italiani. Gli italiani e l'informazione. Relatório, Out. 2010. Disponível em: <http://www.demos.it/a00539.php>. Acesso em: 24 Mar. 2015.

DINIZ, Eduardo; BARBOSA, Alexandre; JUNQUEIRA, Álvaro; PRADO, Otávio. O governo eletrônico no brasil: perspectiva histórica a partir de um modelo estruturado de análise. Revista de Administração Pública, v. 43, p. 23-48, 2009.

FERREIRA, Gil. Espaços discursivos on-line e democracia deliberativa: promessas e limites. In: MORGADO, Isabel; ROSAS, Antonio. Cidadania digital, p.101-116. Portugal: Labcom Books, 2010.

GARETT, Kelly. Protest in an information society: a review of literature on social movements and new ICTs. Information, Communication and Society, v. 9, p. 202-224, 2006.

GOMES, Wilson. Internet e participação política em sociedades democráticas. Revista Famecos, n. 27, 2005.

INSTITUTO BRASILEIRO DE GEOgRAFIA E ESTATÍsTICA (IBGE). Censo 2010. Rio de Janeiro: IBGE, 2010. 
LIMA, Andréia; SILVA, Juliana; MEDEIROS, Liziany; TYBUSHI, Jerônimo. Democracia digital: uma análise do potencial das tecnologias digitais como fator fortalecedor de uma cultura cívica. Reget, v. 19, n. 1, 2015.

MARTINS JUNIOR, José Paulo; DANTAS, Humberto. O índice de participação e a importância da educação. Opinião Pública, v. 10, n. 2, p.268-287, 2004.

MONASTERIO, Leandro Monteiro. Medindo o capital social: uma análise das regiões do Rio Grande do Sul. In: CORREA, Silvio Marcus de Souza. Capital social e desenvolvimento regional, p. 61-84. Santa Cruz do Sul: Edunisc, 2013.

OLIVEIRA, Fábio. Uma nova democracia representativa? Internet, representação política e um mundo em transformação. Revista de Direito Administrativo, v. 264, p. 187-221, 2013.

PUTNAM, Robert David. La tradizione civica nelle regioni italiane. Milano: Arnoldo Mondadori Editore, 1993.

RUEDIGER, Marco Aurélio. Governo eletrônico e democracia: uma análise preliminar dos impactos e potencialidades na gestão pública. Organizações e Sociedade, v. 9, n. 25, p. 29-43, 2002.

SANTOS, Everton Rodrigo; BITARELLO, Jucelaine; MONTARDO, Sandra; PEDDE, Valdir. Contrastes regionais que fazem diferença no Rio Grande do Sul: capital social e desempenho institucional. Revista Brasileira de Gestão e Desenvolvimento Regional, v. 6, n. 2, p. 157-187, 2010.

VERBA, Sidney; NIE, Norman. Participation in America. New York: Harper and Row, 1972.

WINKLER, Ingrid. Participação política mediada pela internet: uso das TIC pelos movimentos sociais em sua atuação política. Anais do VI Encontro de Estudos Organizacionais da Anpad, Florianópolis, Maio 2010. 